\title{
Combining Traditional Face-to-Face Classroom Practices with Computer Mediated Activities for Meaningful Learning Experience
}

\author{
Olubummo, Daniel Adebiyi ${ }^{1}$; Emmanuel, Ikiomoye Douglas²; Otobo, Firstman Noah ${ }^{3}$; \\ Bello, Rotimi-Williams ${ }^{4}$ \\ Department of Computer Science, Federal Polytechnic, Ekowe, Bayelsa State, Nigeria ${ }^{1}$ \\ Department of Mathematical Sciences, University of Africa, Toru-Orua, Bayelsa State, Nigeria ${ }^{2,3,4}$ \\ Correspondence Email:sirbrw@yahoo.com
}

\begin{abstract}
Literacy is defined as the ability to read and write; and these reading and writing must come by learning, and learning, by teaching. But, for a meaningful teaching and learning to be experience, combining traditional face-toface classroom practices with computer mediated activities is not debatable in that, such blended approach will go a long way in reducing the challenges mitigating the zeal towards teaching and learning. Today, there are various available instructional materials that are computer-aided for teaching and learning purposes, which in the past were made of poisonous materials that pose danger to the life of both the teachers and the learners. Apart from all these known facts; two good heads (synergizing traditional face-to-face classroom practices with computer mediated activities) are better than one (sum of their individual effects), so says an adage. In this paper, we set the following as the objectives: 1) to review some learning technologies that are related to blended learning technology; 2) to describe the blended learning models; and 3) to discuss both the advantages and the disadvantages of blended learning. The blended learning principle was mathematically interpreted.
\end{abstract}

Keywords: Computer literacy, Teaching and learning, Blended learning, Classroom, VLE

\section{INTRODUCTION}

In education, there are various approaches to imparting knowledge but, there are basically the technological method and the traditional method. Blended learning as one of the methods falls under the technological method while the method of face-to-face classroom practices falls under the traditional method. Blended learning according to [1], [2], [3], is an approach to education that combines online educational materials and opportunities for interaction online with traditional place-based classroom methods. It requires the physical presence of both teacher and student, with some elements of student control over time, place, path, or pace. According to [4], [5], while students still attend "brick-andmortar" schools with a teacher present, face-to-face classroom practices are combined with computer-mediated activities regarding content and delivery. Because of the contextual nature of blended learning, a worldwide conception of it is not easy to come by [6].

In [7], there were reports that claimed that the difficulties researchers go through in carrying out good research to justify the effectiveness of blended learning was due to the lack of consensus in accepting the hard definition of blended learning. Nonetheless, according to [8], a 2015 meta-analysis that historically looked back at a comprehensive review of evidence-based research studies around blended learning, found commonalities in defining that blended learning was "considered a combination of traditional face-to-face modes of instruction with online modes of learning, drawing on technology-mediated instruction, where all participants in the learning process are separated by distance some of the time as seen in Fig. 1." Having considered this report, with all these evidence-based studies, it was synergistically concluded that student achievement was higher in blended learning experiences when compared to either fully online or fully face-to-face learning experiences [9]. 
Vol. 8, Issue 6, June 2019

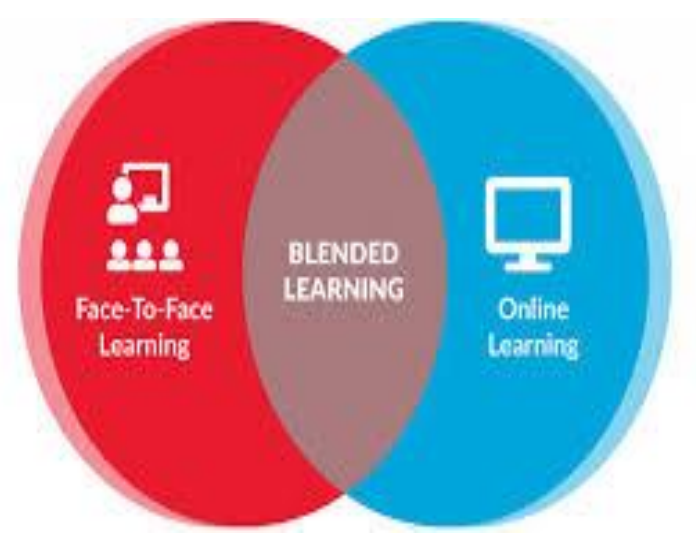

Fig.1 Blended learning [10]

\section{BLENDED LEARNING RELATED LEARNING TECHNOLOGIES}

In [11], computerized learning systems were referred to as electronic educational technology, e-learning, learning platform or learning management system (LMS). The major difference is that VLE and LMS are applications, whereas, the learning platform shares characteristics with an operating system where different educational web-based applications can be run on the platform. The term VLE and learning platform are generically used to describe a range of integrated web-based applications that provide teachers, learners, parents and others involved in education with information, tools and resources to support and enhance educational delivery and management. These terms are broadly synonymous with managed learning environment (MLE).

The application that form part of these online services can include web pages, email, message boards and discussion forum, text and video conferencing, shared diaries, online social areas, as well as assessment, management and tracking tools [12], [13]. The term learning platform refers to a range of tools and services often described using terms such as educational extranet, VLE, LMS, ILMS and LCMS providing learning and content management. The term learning platform also includes the personal learning environment (PLE) or personal online learning space (POLS), including tools and systems that allow the development and management of electronic portfolios. Related concepts of a learning management system (LMS) include content management system (CMS), which properly refers to the organization of the educational or other content, not the overall environment; learning content management system (LCMS), which is more often used for corporate training systems than for systems in education institutions; managed learning environment (MLE), which normally refers to the overall infrastructure in an institution of which the VLE is a component, learning support system (LSS); online learning centre (OLC); or learning platform (LP), education via computer-mediated communication (CMC); or online education.

In educational technology, blended learning can be compared to virtual learning environment (VLE); a web-based platform for the digital aspects of courses of study, usually within educational institutions (Fig. 2). According to [14], VLE platforms commonly allows: 1) content management for creation, storage, access to and use of learning resources; 2) curriculum mapping and planning for lesson planning, assessment and personalization of the learning experience; 3 ) learner engagement and administration for managing access to learner information and resources and tracking of progress and achievement; and 4) real time communication for live video conferencing or audio conferencing. 

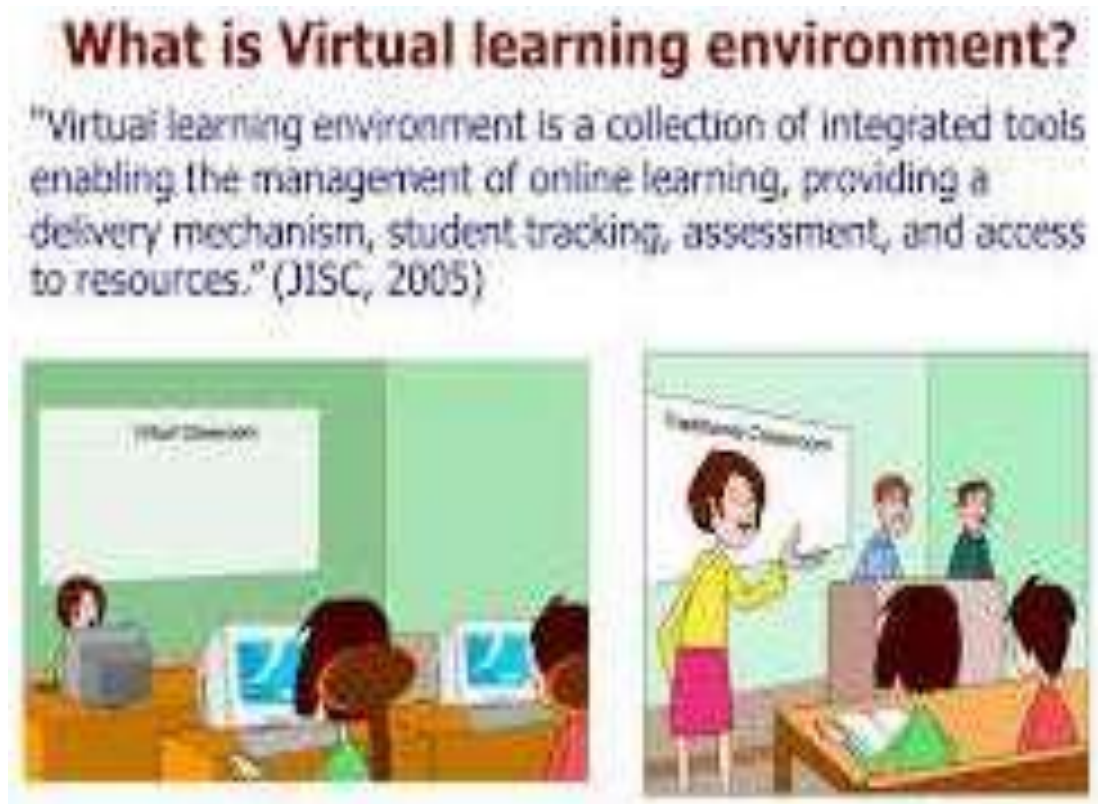

Fig. 2. Virtual learning and non-virtual learning environment [11]

According to [15], training that is technology-based emerged as a substitute to instructor-led training in the 1960s on mainframes and mini-computers. Scale is one of the major advantages that blended learning offers, while on the contrary, one instructor can only teach so many people in the traditional method. PLATO, acronym for Programmed Logic for Automatic Teaching Operations is a system developed by the University of Illinois and Control Data with the history of innovations and coursework offering from elementary to the college level [16]. Due to a number of interface limitations, mainframe-based training gave way to satellite-based live video in the 1970s. The live video was to the advantage of the people who were not computer literate. But to make the live video functional, it involved huge capital; this became the major challenge confronting alternative technology. According to [17], in the early 1990s, CD-ROM became the choice of everyone as a better replacement to the earlier methods of providing technology-based learning as bandwidth through 56k modems were not able to support very high quality sound and video. Tracking coursework that is completed was not that easy for CD-ROM, and this became a serious limitation on its part, so learning management system emerged as a replacement to CD-ROM in order to facilitate coursework progress tracking.

The aviation industry applied the use of learning management system heavily to track: 1) performances on courses; 2) how much time spent; and 3) where someone left off. CD-ROM was used by Boeing Aviation Company to provide training for personnel as approved by AICC, acronym for Aviation Industry Computer-Based Training Committee that was formed in 1988. Modern blended learning is delivered online; [17] opined that CD-ROM could feasibly still be used if a learning management system meets an institution's standards. According to [17], some examples of channels through which online blending learning can be delivered include webcasting (synchronous and asynchronous) and online video (live and recorded). Solutions such as Khan Academy have been used in classrooms to serve as platforms for blended learning [17].

Virtual learning environment is a term that is synonymous to management learning environment; whereas, management learning environment is synonymous to learning management system. Although, individual learning technology mentioned so far look discrete but, in actual fact, they are homogenously related [11]. A VLE is normally not designed for a specific course or subject, but is capable of supporting multiple courses over the full range of the academic program, giving a consistent interface within the institution and to some degree with other institutions using the system. The VLE supports an exchange of information between a user and the learning institute he or she is currently enrolled in through digital mediums like e-mail, chat rooms, web 2.0 sites or a forum thereby helping convey information to any part of the world with just a single click [18]. 
Vol. 8, Issue 6, June 2019

According to [11], one of the processes to enhance the learning experience was the virtual resource room, which is student centered, works in a self-paced format, and which encourages students to take responsibility for their own learning. In virtual mode, the materials are available in the form of computer aided learning program, lecture notes, special self-assessment module. Another mechanism for student to student interaction in a form of simple discussion forum is by using a novel link cyber tutor. This allows the students with an email account to connect with course content and the staff with their doubts and related questions. The students are able to contact the staff without a face to face visit which saves the on campus time. The staff remains anonymous which allows for the several staff to act as a cyber tutor during the course. The students do not remain anonymous although their email addresses are cryptic enough to mask their identity. Students can discuss about the exams, lab reports, posters, lectures, and technical help with downloading materials. The evaluation of the use of virtual resource room is done by surveys, focus groups and online feedback forms.

\section{MODELS OF BLENDED LEARNING}

As earlier iterated, there were reports that claimed that the difficulties researchers go through in carrying out good research to justify the effectiveness of blended learning was due to the lack of consensus in accepting the hard definition of blended learning. Nonetheless, the following are the distinct blended learning models suggested by some educational researchers. These models in some literature are taken to be four, but for better understanding and explanation, we have decided to separate the models to ten.

1. Face-to-face driver model-In any classroom where students perform at various levels of skill and ability; face-to-face driver model is the best option. Because most of the class is led by face-to-face lessons, face-to-face driver model therefore becomes synonymous model to traditional teaching. For students that are not finding it easy to cope during classroom activities, online instruction is introduced for such category in order to engage and supplement the classroom lessons. Individual rotation model can perfectly fit into this model as shown in Fig. 5.

2. Center rotation model-Different learning centers are created by teachers in this model (Fig. 3). Students' needs under this model are easily taken care of, in the sense that using digital learning tools at rotating centers; teachers are able to rotate among the students using the face-to-face teaching time with more attention on a particular subject before rotating to digital learning centers to solve any other pending problems. Basically, timetable is designed for students to work at different centers, rotating between face-to-face instruction and computer mediated assignments. This rotation arrangement gives the students time and focus they need on certain subjects while granting different learners available avenues towards mastering the material. For example, a class can be divided based on their skill levels in arithmetic and reading. For the group that record good performance in reading, but not in math, more face-to-face teaching time can be dedicated with more attention on math concepts before rotating to digital learning centers for reading comprehension.

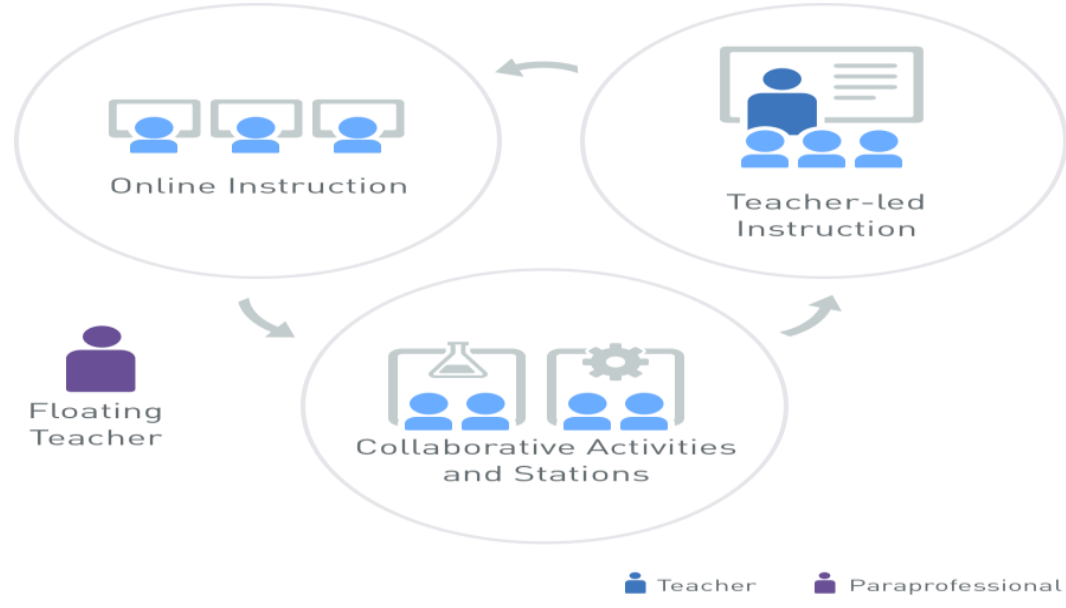

Fig. 3. Center rotation model [10]

3. Self-blend model-In this model, students are given the opportunity to take classes beyond the general courses approved with online classes. Preparation for external examinations such as general certificate of education (GCE) sometimes demands self preparation from students, so, students who want to take such examination or show a 
Vol. 8, Issue 6, June 2019

particular interest in a subject are good candidates for self-blended learning. Individual student goals and skills matter in choosing this model.

4. Online driver model-This model relies solely on online teaching delivery. Students, due to one reason or another receive instruction and assignments via online platforms. This is the model that fits into the system use by National Open University of Nigeria (NOUN), whereby students work and at the same time study. In this model, educators act as facilitators and give students the opportunity to contact them online and engage in online messaging should they need further assistance. As earlier said, this model works well for students who need flexibility for other obligations or students who want to progress much faster than would be possible in a traditional school setting.

5. Lab rotation model- This model, like center rotation, allows students to rotate through centers on a fixed schedule (Fig. 4). Nonetheless, in this case, online learning occurs in a dedicated computer lab. That is, the entire curriculum is delivered via a digital platform but in a consistent physical location. This model allows for flexible scheduling arrangements with teachers and other paraprofessionals, and enables schools to make use of existing computer labs.

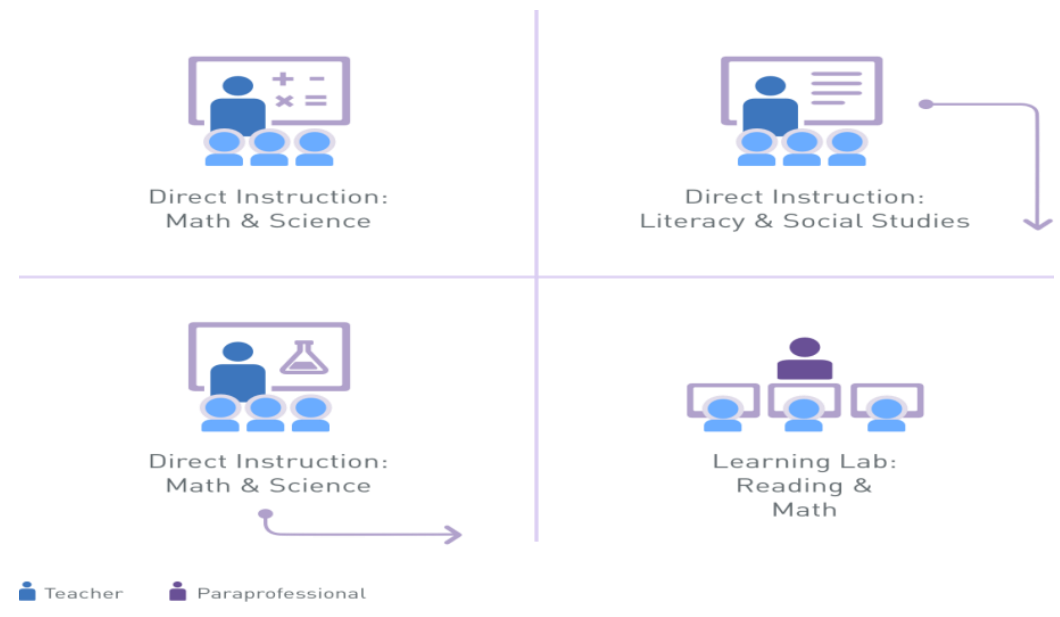

Fig. 4. Lab rotation model [10]

6. Individual rotation model-This allows students to rotate through centers, but on individual schedules set by a teacher or software algorithm. Unlike other rotation models, students do not necessarily rotate to every center; they rotate only to the activities scheduled on their playlists.

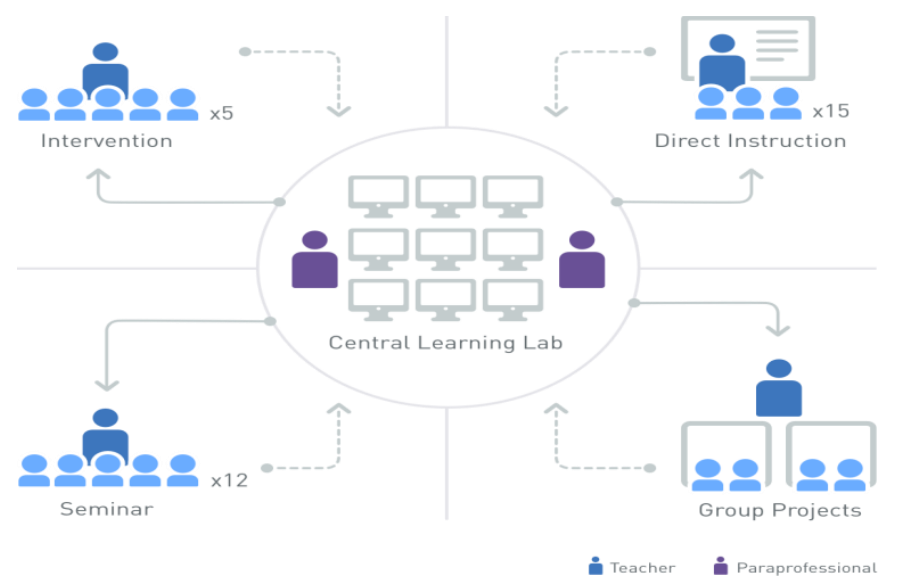

Fig. 5. Individual rotation model [10]

7. Flipped classroom model- This model flips the traditional relationship between class time and homework (Fig. 6). Students learn at home via online coursework and lectures, and teachers use class time for teacher-guided practice or projects. This model enables teachers to use class time for more than delivering traditional lectures. 
Vol. 8, Issue 6, June 2019

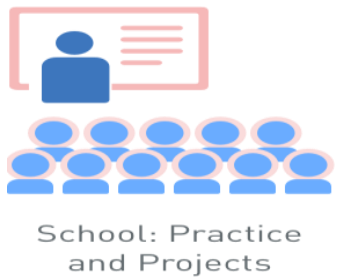

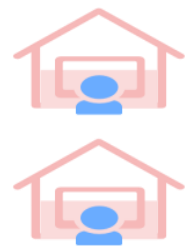

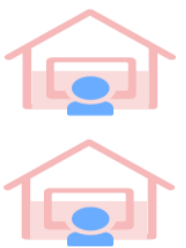

Home: Online Instruction and Content

Fig. 6. Flipped classroom model [10]

8. Flex model-In this model, most of the curriculum is delivered via digital platform. This lets students move on fluid schedules among learning activities according to their needs. Computer mediated learning otherwise known as online learning is the backbone of student learning in a flex model. Teachers are available for face-to-face consultation; support and instruction on a flexible arrangement while students work through course curriculum and content. This model can give students a high degree of control over their learning.

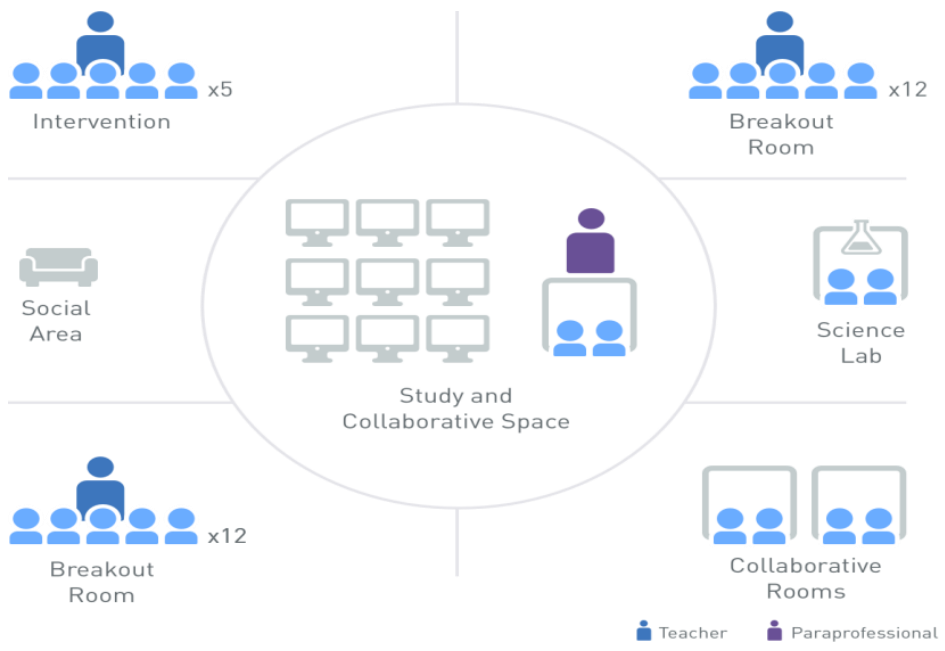

Fig. 7. Flex Model [10]

9. A La Carte model-This model enables students to take an online course with an online teacher in addition to other face-to-face courses, which often provides students with more flexibility over their schedules. A La Carte courses can be a great option when schools can't provide particular learning opportunities, such as elective course, making it one of the more popular models in schools that are already into blended learning. This model is synonymous to self-blend model. 
Vol. 8, Issue 6, June 2019

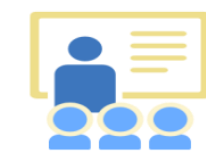

School

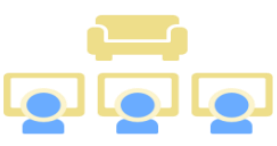

Learning Lab

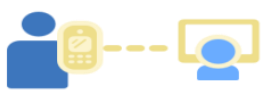

Online Teacher

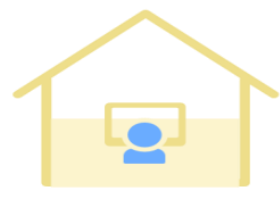

Home

Fig. 8. A La Carte model [10]

10. Enriched virtual model-This model is an alternative to full-time online school that allows students to complete the majority of coursework online at home or outside of school, but attend school for required face-to-face learning sessions with a teacher. Unlike the flipped classroom, enriched virtual programs for example, usually don't require daily school attendance; some programs may only require twice-weekly attendance.

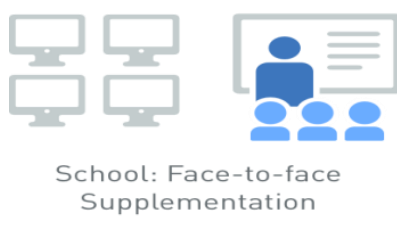

Fig. 9. Enriched virtual model [10]

Blended learning as shown in Fig. 1, can be mathematically interpreted as follows:

\section{If,}

The intersection of two sets $\mathrm{A}$ and $\mathrm{B}$, denoted by $\mathrm{A} \cap \mathrm{B}$, is the set of all objects that are members of both the sets $\mathrm{A}$ and B. In symbols,

$A \cap \mathrm{B}=\{x: \mathrm{x} \varepsilon A$ and $x \in \mathrm{B}\}$.

Where face-to-face learning and online learning are the elements that are members of both the sets $\mathrm{A}$ and $\mathrm{B}$ respectively, and $x$, is the intersection result of $\mathrm{A}$ and $\mathrm{B}$, which is blended learning

Then, $\mathrm{x}$ is an element of the intersection $\mathrm{A} \cap \mathrm{B}$ if and only if $x$ is both an element of $\mathrm{A}$ and an element of $\mathrm{B}$.

For example:

The intersection of the sets \{face-to-face learning $\}$ and \{online learning $\}$ is $\{$ blended learning .

\section{ADVANTAGES AND DISADVANTAGES OF BLENDED LEARNING}




\subsection{Advantages}

In [11], the advantages of blended learning are as follows: 1) learning is not restricted to a particular place (i.e. the classroom) as material can be accessed from anywhere using the internet; 2) learning is not restricted to a particular time as students can access all the materials at anytime; 3) students can repeat the material many times that helps them revise; 4) the multimedia material will help present the material in a more interesting way; 5) students can try the procedures many times until they get them right; 6) there is an option for the instructor to test learners on each procedure taught; 7) the students can access the system using the internet and can therefore practice in their own time.[19]

Also, blended instruction is reportedly more effective than purely face-to-face or purely online classes [20] in that, blended learning methods raise the performance levels of student than face-to-face learning. By using a combination of digital instruction and face-to-face instruction, students on their own can work with new concepts which enable teachers to circulate and support individual students who may need special attention. As opined by [20], rather than playing to the lowest common denominator-as they would in traditional classroom-teachers can streamline their instruction to help students reach their full potential. The use of information and communication technologies has been found to improve student attitudes towards learning [21]. By incorporating information technology into class activities, communication gap between lecturers and students has been filled, and the use of computer-based assessment modules has greatly helped students to evaluate their understanding of course material [22].

E-library, a blended learning tool, is an effort made to: 1) reduce the burden of purchasing pricey textbooks; and 2) to give both students and teachers unlimited and quick access to the online textbooks when need arises. By this, blended learning can lower costs as classrooms are put in the online system.

\subsection{Disadvantages}

In [11], the disadvantages of blended learning are as follows: 1) the technological tools of blended learning are expensive; 2) IT literacy and training is needed to take advantage of what a blended learning has to offer, and the time and finance to do the training may not be available; 3) blended learning could seriously be to the disadvantage of those students who do not have pervasive and ubiquitous internet access at home even in their classroom; 4) time and internet service subscription are needed for the teacher to upload content to the blended leaning online platform. Unless successfully planned and executed, blended learning could have disadvantages in technical aspects since it has a strong dependence on the technical resources or tools with which the blended learning experience is delivered. These tools need to be reliable, easy to use, and up to date, for them to have a meaningful impact on the learning experience [23].

From an educator's perspective, most recently, it has been noted that providing effective feedback is more timeconsuming (and therefore more expensive) when electronic media are used, in comparison to traditional (e.g. paperbased) assessments [24].

\section{CONCLUSION}

This paper has been able to present blended learning as the ideal model for learning in educational technology. The individual role of blended learning related technologies and models was iterated in the course of this study. So many advantages were attributed to blended learning as instructional and learning medium; blended learning synergizes traditional face-to-face classroom practices with computer mediated activities for better learning experience. As uninterrupted network and internet availability become the number one determinant for a successful implementation of blended learning, so, any attempt to incorporate blended learning strategies into education's didactical strategy means that consideration must be given to network infrastructure.

It is also necessary to know that, while computer mediated learning technology is setting new ways for students to be in control of their educational career, teachers' position in educational activities cannot be under estimated because much is still expected from them for students' success. So, before executing any blended learning model, it is necessary for consensus to be reached among the teachers and the students on how the model will help achieve the overall learning objectives. 


\author{
Vol. 8, Issue 6, June 2019
}

\title{
REFERENCES
}

[1]. Banditvilai, C. (2012). "Enhancing Students' Language Skills through Blended Learning," The Electronic Journal of e-Learning, volume 14, issue 3, pp. 220-229.

[2]. Friesen, N. (2012). Report: Defining blended learning, Learning Space.

[3]. Staker, H.; Horn, M.B. (2012). Classifying K-12 Blended Learning, Innosight Institute, Inc. www.innosightinstitute.org

[4]. Strauss, V. (2012). "Three fears about blended learning", The Washington Post.

[5]. McGee, P., Reis, A. (2012). Blended Course Design: A Synthesis of Best Practices, Journal of Asynchronous Learning Networks, v16, n4, pp.7-22.

[6]. Moskal, P.; Dziuban, C.; Hartman, J. (2012). "Blended learning: A dangerous idea?", Internet and Higher Education. 18: 15-23. doi:10.1016/j.iheduc.2012.12.001

[7]. Oliver, M.; Trigwell, K. (2005). "Can 'Blended Learning' Be Redeemed?", E-Learning. 2 (1): 17-26. doi:10.2304/elea.2005.2.1.17

[8]. Siemens, G.; Gašević, D.; Dawson, S. (2015). Preparing for the Digital University: a review of the history and current state of distance, blended, and online learning. Pg. 62. Athabasca University. Retrieved from http://linkresearchlab.org/PreparingDigitalUniversity.pdf

[9]. Siemens, G.; Gašević, D.; Dawson, S. (2015). Preparing for the Digital University: a review of the history and current state of distance, blended, and online learning. Pg. 71. Athabasca University. Retrieved from http://linkresearchlab.org/PreparingDigitalUniversity.pdf

[10]. www.blendedlearning.org

[11]. Bello, R.W.; Otobo, F.N.; Eru, E.J. (2018). "Virtual learning environment-Some realities," International Research Journal of Advanced Engineering and Science, Volume 3, Issue 2, pp. 372-374.

[12]. JISC."Inform1.2002"Retrieved28August2007,from http://www.jisc.ac.uk/publications/publications/pub_inform1.aspx.

[13]. Posey, G.; Burgess, T.; Eason, M.; Jones, Y. (2012). "Advantages and Disadvantages of the Virtual Classroom and the Role of the Teacher" (PDF). Alabama A and M University, P.O. Box 429, Normal, AL 35762.

[14]. Husain, S. N. (2012). "Online communication between home and school. Case study: Improving the usability of the Unikum e-service in the primary schools of Tierp municipality" (PDF). Department of Informatics and Media.

[15]. Bersin, J. (2004). "How Did We Get Here? The History of Blended Learning" (PDF). The Blended Learning Book: Best Practices, Proven Methodologies, and Lessons Learned. Wiley. ISBN 978-0-7879-7296-7.

[16]. Small, D.; Small, S. (1984). Plato Rising, Online learning for Atarians. Atarimagazines.com. Retrieved 2013-10-24.

[17]. Coach resources. (2012). "in the real world | Coach resources", Khan Academy. Archived from the original on 2013-10-23. Retrieved 2013-1024.

[18]. Peat, M. "Towards First Year Biology online: a virtual learning environment", Educational Technology and Society. 3(3): 203-207, 2000. JSTOR jeductechsoci.3.3.203.

[19]. Chris, L.; Roger, B.; Tony, P. (2012). AS and A level Computing Course book, Cambridge University Press, Cambridge International.

[20]. Saritepeci, M.; Cakir, H. (2015). "The effect of blended learning environments on student motivation and student engagement: A study on social studies course", Education and Science, Vol. 40, No. 177, pp. 203-216. DOI: 10.15390/EB.2015.2592

[21]. Alexander, S. (2010). "Flexible Learning in Higher Education", In Penelope Peterson; Eva Baker; Barry McGaws (eds.), International Encyclopedia of Education (Third ed.). Oxford: Elsevier. pp. 441-447. doi:10.1016/B978-0-08-044894-7.00868-X. ISBN 9780080448947.

[22]. Alexander, S.; McKenzie, J. (1998). "An Evaluation of Information Technology Projects for University Learning", Canberra, Australia: Committee for University Teaching and Staff Development and the Department of Employment, Education, Training and Youth Affairs.

[23]. Garrison, D. R.; Kanuka, H. (2004). "Blended learning: Uncovering its transformative potential in higher education", The Internet and Higher Education. 7 (2): 95-105. doi:10.1016/j.iheduc.2004.02.001

[24]. Grieve, R.; Padgett, C. R.; Moffitt, R. L. (2016). "Assignments 2.0: The role of social presence and computer attitudes in student preferences for online versus offline marking", The Internet and Higher Education. 28: 8-16 doi:10.1016/j.iheduc.2015.08.002 